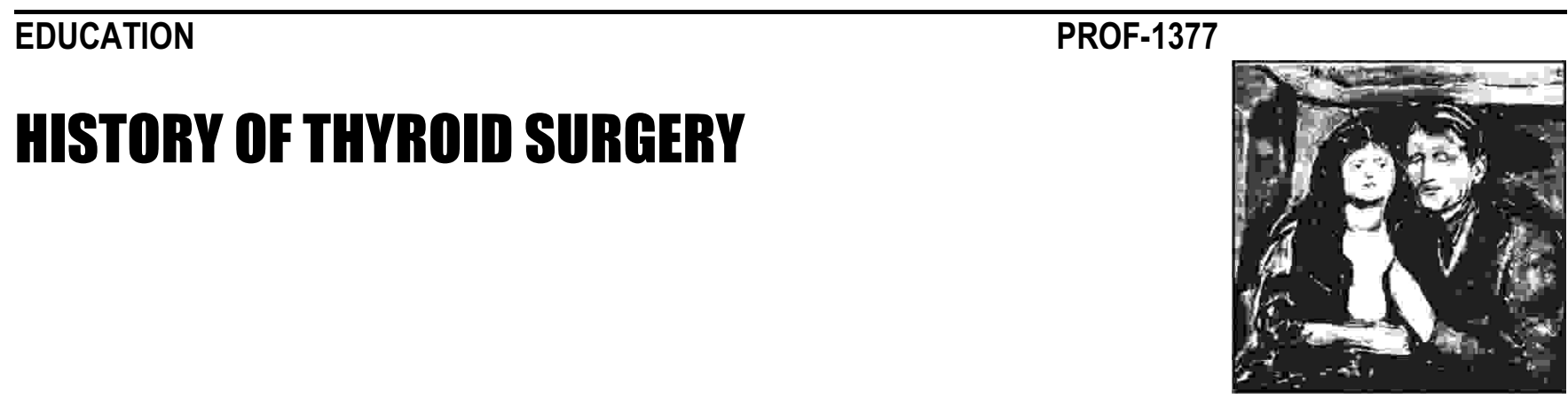

DR. AWAIS SHUJA, MRCS

Senior Registrar (General Surgery)

Independent Medical College

Faisalabad.

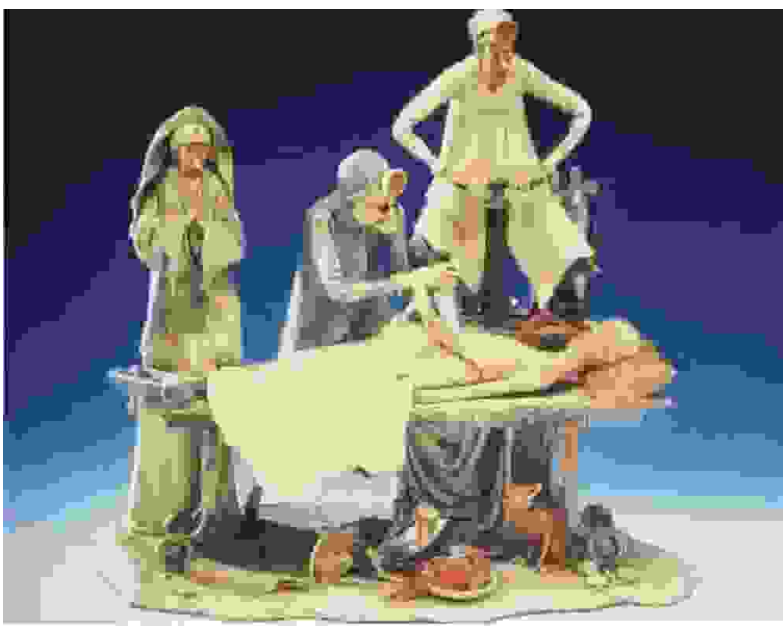

Fig-11.1 Thyroid Surgery in the past

Thyroid surgery has followed all the steps of evolution to reach the time of endoscopic surgery. Thyroid gland was first described by VESALIUS (1514-1564) in 1543, he called it Glandulare laryngis and thought it produced fluid to lubricate larynx. First available illustrations are by Leonardo Davinci.

\section{ORIGIN OF WORD THYROID}

The word thyroid originated from thyreos a Greek word meaning shield. It was first used by Thomas Wharton
(1614-1673) of London. He named it as 'Glandular thyroideis' in 1656.

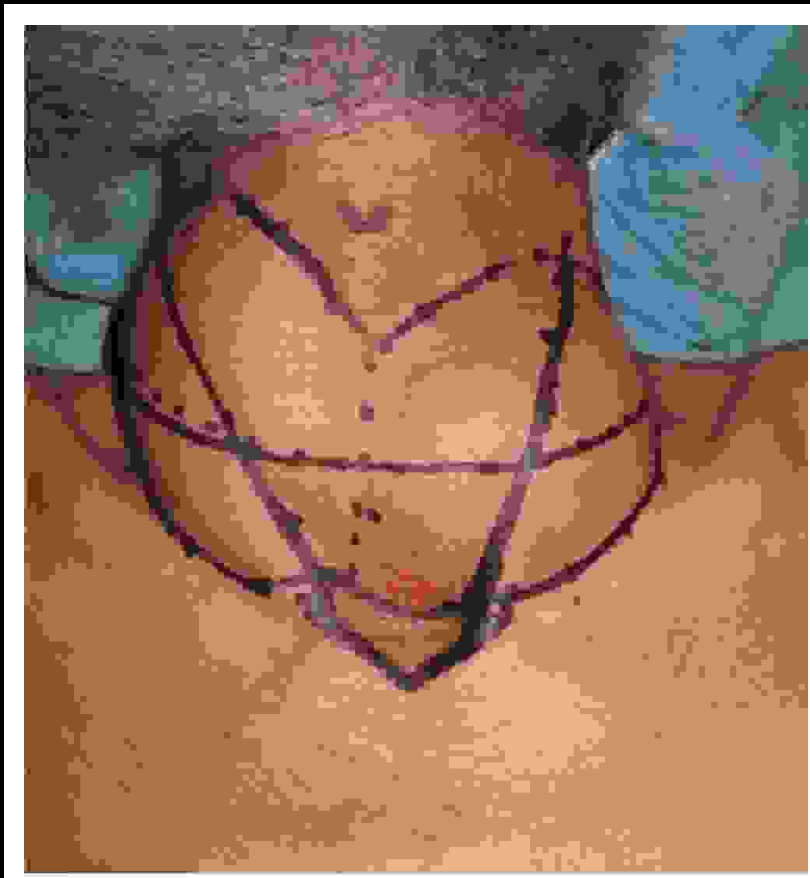

Fig-11.2 Preparation for Thyroid Surgery

Enlargement of thyroid gland produced obvious physical changes in the neck. In old times it was called struma 
(Latin for a swollen gland), bronchocele (a cystic mass in the neck) and goiter (Latin word gutter meaning throat). This last term is in use nowadays.

\section{ANCIENT TIMES}

Thyroid surgery has been performed since ancient times. In 1st century $A D$ Celsus, the Roman encyclopedia reported the operation for removal of such a mass was dangerous.

Albucasis the 11th century surgeon of corodoba (Spain) also explained extirpation of the gland. Certainly the surgeons of Salerno in 12th century were transfixing large goiters with Setons, thread passed through the mass to produce suppuration as well as treating their patients; with seaweeds either dried or burned.

These methods were published by Roger Frugardi in 1170. Technical improvements did not occur until the middle of the 19th century. In the interim period, appalling results led in 1646 to the imprisonment of a surgeon for his work and to a total ban on thyroid surgery by the French academy of medicine in 1850 .

\section{DAWN OF NEW AGE}

The first documented partial thyroidectomy was carried out by Pierre Joseph Desault in 1791. He removed a 4 $\mathrm{cm}$ mass from thyroid through a vertical incision, tying of superior /inferior thyroid arteries and then dissecting the gland from trachea. Caleb hillier Parry of Bath who identified exophthalmic goitre in 1786 before graves description in 1835. Parry's account was published post humously in 1825 .

Thyroid surgery remained in its infancy until the second half 19th century, so too was medical treatment. Discovery of iodine in burned ash of seaweed in 1811 led to successful treatment of some goitres.

Thyroid surgery came of age because of new developments as use of ether anaesthesia in 1846, antisepsis in 1867 and first effective artery forceps in 1870 allowed unhurried and safer dissection.

\section{MODERN THYRIOD SURGERY}

Modern thyroid surgery owes much to one man called THEODOR KOCHER, professor of Surgery at Berne, Switzerland. He can be called father of thyroid surgery.

He reported 146 thyroidectomies from 1850 to 1877 worldwide with mortality $21 \%$. He also reported 600 cases performed with $0.5 \%$ mortality in 1898 which revolutionized the technique and method of thyroid surgery. This earned him Nobel Prize for medicine in 1909.the principles of thyroid surgery described by Theodor kocher are still valid and became foundation for all future refinements.

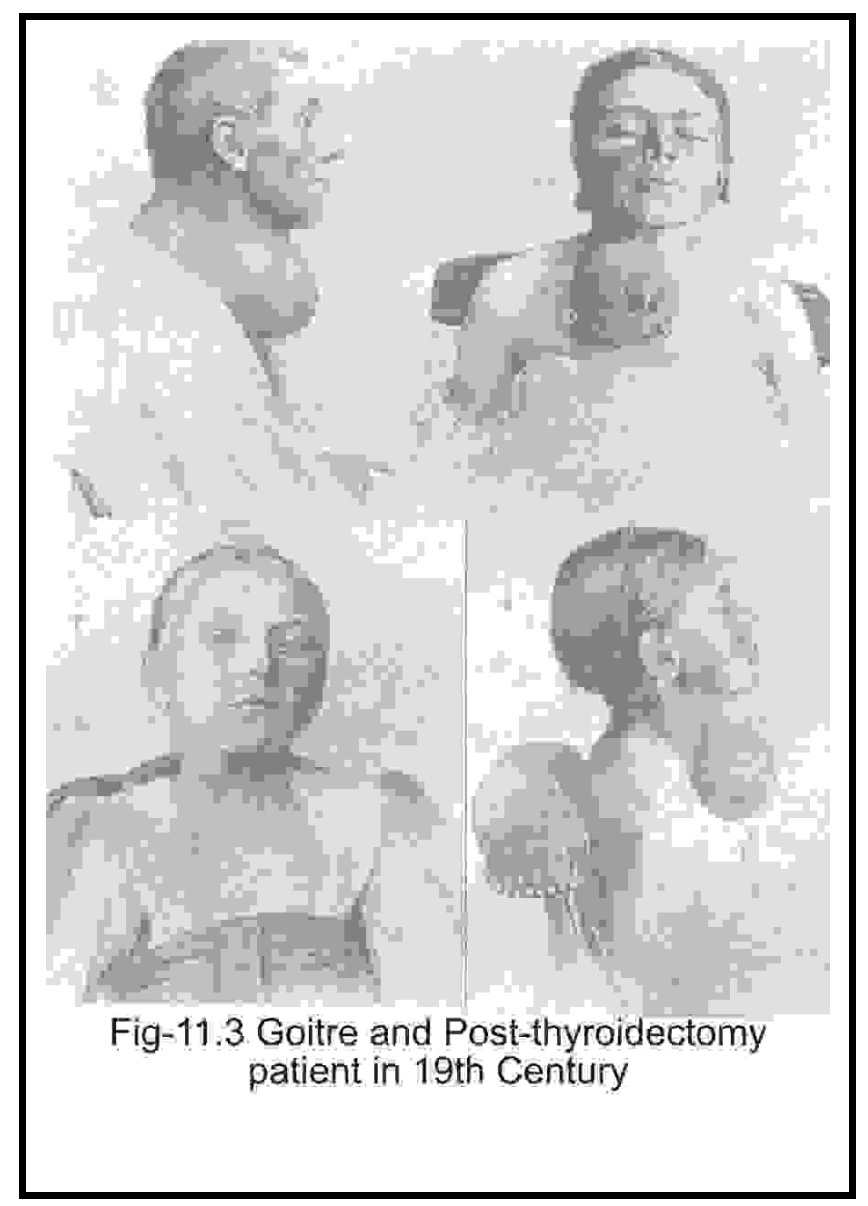

\section{0th CENTURY AND ONWARDS}

At the turn of century Thomas Dunhill Peel described near total thyroidectomy for thyrotoxicosis. He by 1910 had done 312 operations, of which 200 were for 
exoph-thalmic goitre. Astoundingly he achieved mortality rate less than $3 \%$ which was treated with disbelief and derision by surgical intelligentsia.

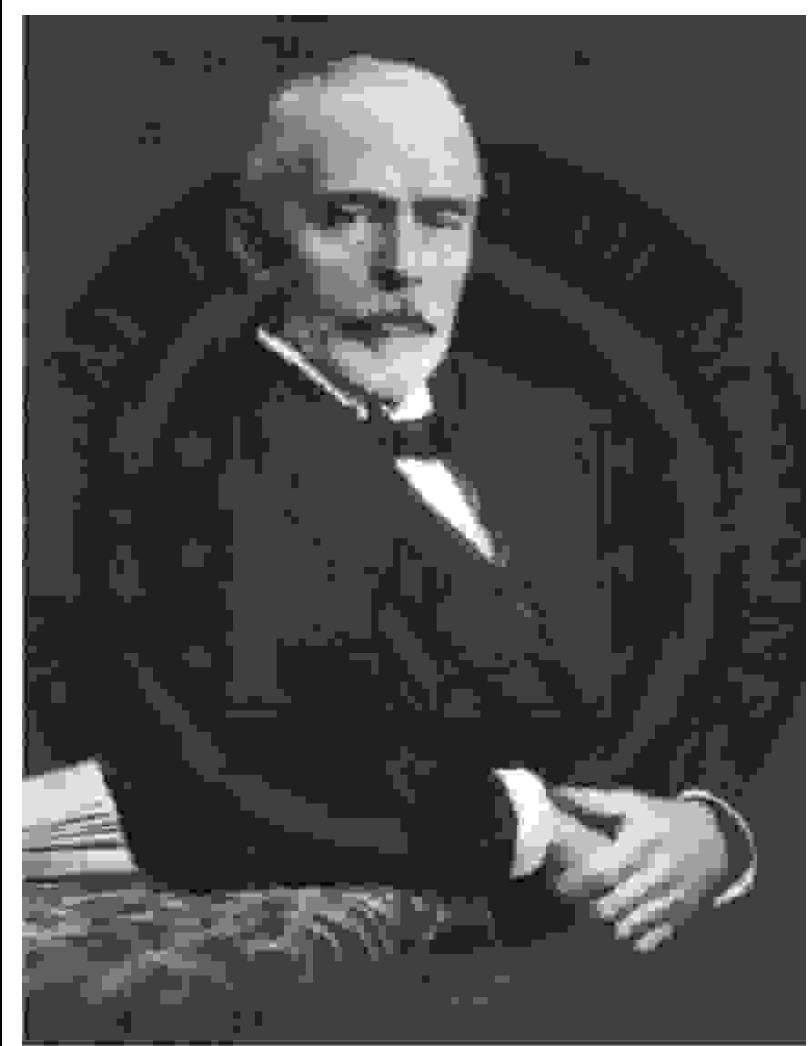

Fig-11.4 Father of Thyroid Surgery Prof. Theodor Kocher

In 1890, European advances in thyroidectomy were taken to the USA by William Halsted of Baltimore, Charles Mayo of Rochester and George Crile of Cleveland, Ohio and subse-quently by Frank Lahey. In 1938 he advised lateral ligation of inferior thyroid artery to avoid nerve injury and recorded a nerve palsy rate of only $0.3 \%$.

In late 19th century enlarged goitre was treated with divison of isthmus. This was described by Bernhardt Riedel in 1896 who also explained Riedel's lobe. in 1902 and 1904 DeQuervains thyroiditis was described in 1912 Hakara Hashimoto described chronic lymphoid thyroiditis.
Further improvements in medical treatment of thyroid disease took place in early 20th century when Edward Kindall of Mayo Clinic in 1914 on Christmas day derived thyroxin, making the treatment of hypothyroidism easy and safe.

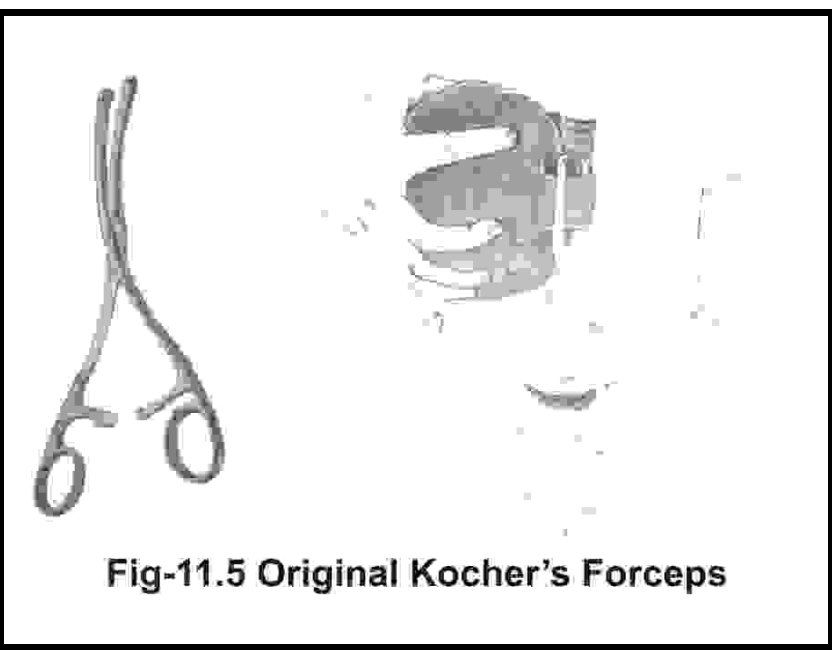

Post World War II progress included positive pressure ventilation and better antithyroid drugs such as propranolol introduced in 1965 improved outcomes of treatment. Ultrasound and CT scan further refined the methods of assessment. In 1952 FNAC which was described by Soderstrom which improved the diagnosis of thyroid disease.

\section{NEW MILLENNIUM}

This millennium is of minimally invasive techniques. This century has seen new development of video assisted thyroidectomy by Micoli in Italy.MRI and PET scans are new developments in assessment methods.Thyroid surgery has come a long way but the best days are still to come.

\section{REFERENCES}

1. A E Giddings: The history of Thyroidectomy; J R SOC MED 1998: 91 (SUPP33) 3-6.

2. Harold Ellis: A History of Surgery. 2001, Chapter 13. page 199- 205 